\title{
Autosomal recessive cutis laxa type 2B
}

INSERM

\section{Source}

INSERM. (1999). Orphanet: an online rare disease and orphan drug data base. Autosomal recessive cutis laxa type 2B. ORPHA:357064

Autosomal recessive cutis laxa type $2 \mathrm{~B}$ is a rare, hereditary, developmental defect with connective tissue involvement characterized by cutis laxa of variable severity, in utero growth restriction, congenital hip dislocation and joint hyperlaxity, wrinkling of the skin, in particular the dorsum of hands and feet, and progeroid facial features. Hypotonia, developmental delay, and intellectual disability are common. In addition, cataracts, corneal clouding, wormian bones, lipodystrophy and osteopenia have been reported. 